\title{
Crescimento de plantas e vigor de sementes de feijão em resposta à aplicação exógena de ácido giberélico
}

\section{Plant growth and vigor of bean seeds in response to the exogenous application of gibberellic acid}

\author{
Tiago Pedó1, Emanuela Garbin Martinazzo², Marcos Antonio Bacarin ${ }^{1}$, Irajá Ferreira Antunes³, \\ Felipe $\mathrm{Koch}^{4}$, Manoela Andrade Monteiro ${ }^{4}$, João Roberto Pimentel ${ }^{4}$, Cristian Troyjack ${ }^{4 *}$, \\ Francisco Amaral Villela ${ }^{1}$ e Tiago Zanatta Aumonde ${ }^{1}$
}

${ }_{1}$ Prof. Dr. Faculdade de Agronomia Eliseu Maciel, Departamento de Fitotecnia, Programa de Pós-Graduação em C\&T de Sementes, UFPel, Bolsista de Produtividade em Pesquisa do CNPq - PQ2 2 Prof. Dra. Instituto de Biologia - Universidade Federal do Rio Grande - FURG

${ }^{3}$ Dr. Pesquisador da Embrapa Clima Temperado, Pelotas, RS, Brasil

4 Doutorando (a) em C\&T de Sementes, Bolsista CNPq, UFPel, Pelotas, RS, Brasil

(*E-mail: cristiantroyjack@hotmail.com)

http://dx.doi.org/10.19084/RCA17169

Recebido/received: 2017.07.09

Recebido em versão revista/received in revised form: 2018.01.11

Aceite/accepted: 2018.03.06

\section{R E S U M O}

O trabalho objetivou avaliar comparativamente o crescimento e a expressão do vigor de sementes de feijão provenientes de plantas submetidas à aplicação de ácido giberélico. Os tratamentos consistiram na aplicação de ácido giberélico nas concentrações de zero; 50; 100 e 200 mg.L-1 no estádio V2. As coletas para análise de crescimento foram realizadas em intervalos regulares de sete dias após a semeadura, até as plantas atingirem o estádio R9. Em cada coleta, as plantas foram separadas em órgãos, para a determinação do crescimento e da partição de matéria seca. Além disso, determinou-se o índice de colheita, massa de mil sementes, número de sementes por planta, inserção da primeira vagem, comprimento e matéria seca total de plântulas. A matéria seca total, as taxas de produção de matéria seca e a eficiência de conversão de energia solar são superiores em plantas submetidas à aplicação exógena de ácido giberélico. O índice de colheita bem como o número de sementes por planta apresentam uma tendência de redução com a elevação da concentração de ácido giberélico. Contudo, a massa de mil sementes tende a ser superior na dose de $50 \mathrm{mg}$. $\mathrm{L}^{-1}$. O vigor de sementes de feijão, avaliado pelo teste de comprimento de plântulas, é alterado com aplicação de ácido giberélico.

Palavras-chave: Phaseolus vulgaris L., matéria seca, área foliar, regulador crescimento.

\begin{abstract}
A B S T R A C T
The objective of this work was to evaluate the growth and vigor expression of bean seeds from plants submitted to the application of gibberellic acid. The treatments consisted of the application of gibberellic acid in concentrations of zero; 50; 100 and $200 \mathrm{mg} . \mathrm{L}^{-1}$ in the V2 stage. The samples for growth analysis were performed at regular intervals of seven days after sowing, until the plants reached the R9 stage. At each collection, the plants were separated into organs for determination of growth and dry matter partition. In addition, the harvest index, mass of one thousand seeds, number of seeds per plant, insertion of the first pod, length and total dry matter of seedlings were determined. Total dry matter, dry matter production rates and solar energy conversion efficiency are higher in plants submitted to the exogenous application of gibberellic acid. The harvest index as well as the number of seeds per plant present a tendency of reduction with the increase of the gibberellic acid concentration. However, the mass of one thousand seeds tends to be higher in the dose of $50 \mathrm{mg} . \mathrm{L}^{-1}$. The vigor of bean seeds, evaluated by the test of seedling length, is altered with application of gibberellic acid.
\end{abstract}

Keywords: Phaseolus vulgaris L., dry matter, leaf area, growth regulator. 


\section{INTRODUÇÃO}

O feijão (Phaseolus vulgaris L.) é produzido em todo o território do Brasil e seus grãos apresentam elevados conteúdos de proteína e lisina. A dificuldade de colhê-lo mecanicamente é um dos principais entraves na produção do feijão (Baldissera et al., 2012), devido principalmente à baixa inserção das vagens em relação à superfície do solo (Furlani et al., 2008; Silva et al., 2008, 2013). Peske et al. (2012) observaram que a oscilação de umidade e de temperatura ambiental conduziu a redução da qualidade fisiológica de sementes de soja. Sendo assim, é de prever que, por essa oscilação ambiental, o contato ou a proximidade das vagens com o solo pode resultar na diminuição do vigor das sementes de feijão acarretando perdas na pré-colheita.

A arquitetura da planta constitui-se em fator inerente ao genótipo e pode ser relacionada com a produtividade vegetal (Matos Filho et al., 2009) e com a eficiência na colheita mecanizada (Cato e Castro, 2006; Silva et al., 2008), podendo ser modificada pelo emprego de substâncias sintéticas (Rademacher, 2000; Souza et al., 2010a; Taiz e Zeiger, 2013).

Existem cinco tipos de hormônios que regulam o desenvolvimento vegetal, sendo eles as auxinas, giberelinas, citocininas, etileno e ácido abscísico. Também existem evidências da existência de hormônios vegetais esteróides que constitui uma variada gama de efeitos morfológicos no desenvolvimento da planta (Taiz e Zeiger, 2013).

Alguns reguladores de crescimento como auxinas, citocininas e giberelinas estimulam o crescimento inicial da parte aérea das plantas (Pavlista et al., 2006; Lana et al., 2009) e outros como cloreto de clorocolina, cloreto de clormequat, cloreto de mepiquat, etiltrinexapac reduzem o alongamento do caule e influenciam o desenvolvimento reprodutivo pela indução da floração e modificam o desenvolvimento de sementes (Correia e Leite, 2012; Rademacher, 2000).

As giberelinas compõem grupo de hormônios vegetais com ação no alongamento e na divisão celular (Buchanan et al., 2015), sendo obtidas de forma sintética na forma de ácido giberélico (Carraher Jr. et al., 2010). A concentração deste regulador e a sensibilidade do tecido vegetal a este composto determina a resposta de crescimento e de desenvolvimento da planta (Mir et al., 2010). Sendo assim, pelo fato de as giberelinas promoverem o crescimento inicial da parte aérea, a aplicação exógena de ácido giberélico em plantas de feijão pode influenciar o crescimento das plantas e, consequentemente, a inserção da primeira vagem o que facilita a colheita mecanizada, conduzindo a obtenção de sementes de qualidade fisiológica superior (Leite et al., 2003; Swarnkar et al., 2004; Vichiato et al., 2007; Weiss e Ori, 2007).

Os reguladores de crescimento são transportados tanto via xilema quanto pelo floema, sendo o ambiente, um dos fatores responsáveis pela modificação na distribuição entre as diferentes estruturas da planta. A concentração do produto aplicado e a sensibilidade do tecido são preponderantes na obtenção da resposta de desempenho vegetal (Taiz e Zeiger, 2013). Os reguladores de crescimento, podem atuar de forma similar aos hormônios, regulando a máxima expressão do potencial genético, elevando a produção e a alocação de matéria seca, assim, modificando a produtividade dos cultivos (Mir et al., 2010). Segundo Pereira et al. (2001), Khan et al. (2002) e Mir et al. (2010), o aumento da matéria seca em resposta à aplicação de ácido giberélico, resulta da maior absorção de minerais e da superior produção de assimilados.

O crescimento das plantas consiste na produção e distribuição de carbono entre os diferentes órgãos da planta como resultado da interação entre o genótipo e o meio ambiente onde são cultivadas. Então, uma análise de crescimento é um método bastante barato e preciso para avaliar o crescimento da planta sob diferentes condições de manejo e meio ambiente (Aumonde et al., 2013). Esta análise permite a inferência da contribuição por diferentes processos fisiológicos de crescimento sobre sistemas de produção e práticas de manejo para o desempenho da planta, bem como, a descrição de condições morfofisiológicas das plantas, sendo o primeiro passo na interpretação e análise da produção primária (Pedó et al., 2013; Lopes e Lima, 2015).

A qualidade das sementes produzidas possui relação aos fatores bióticos e abióticos que atuam de forma direta ou indiretamente sobre a planta 
sendo expressa pela interação dos componentes genéticos, físicos, fisiológicos e sanitários (Carvalho e Nakagawa, 2012). Fatores diretos atuam sobre a semente, enquanto, os indiretos afetam processos fisiológicos e bioquímicos que ocorrem na planta matriz, alterando a partição de assimilados entre os diferentes órgãos, a biossíntese de compostos e o vigor de sementes (Peske et al., 2012).

Perante o exposto, o objetivo deste trabalho foi avaliar a influência da aplicação exógena de acido giberélico no crescimento de plantas de feijão e na expressão do vigor das sementes produzidas.

\section{MATERIAL E MÉTODOS}

O experimento foi realizado no período da "safrinha", que corresponde a semeadura a partir de janeiro, nas coordenadas geográficas de latitude $31^{\circ} 52^{\prime} \mathrm{S}$, longitude $52^{\circ} 21^{\prime} \mathrm{W}$ e altitude $13 \mathrm{~m}$, no Estado do Rio Grande do Sul. O clima dessa região é temperado com chuvas bem distribuídas e verão quente, sendo do tipo Cfa pela classificação de Köppen. Os dados de temperatura e radiação solar (Figura 1a e 1b) verificados durante o período de condução do experimento foram obtidos por meio do boletim da Estação Agroclimatológica de Pelotas localizada a 100 metros do local de realização do experimento. A temperatura mostrou tendência à ascensão até os 28 dias após a emergência com posterior declínio, enquanto, a radiação solar foi decrescente ao longo do ciclo das plantas de feijão dentro dos padrões normais para a época do ano (Sartori, 2003).

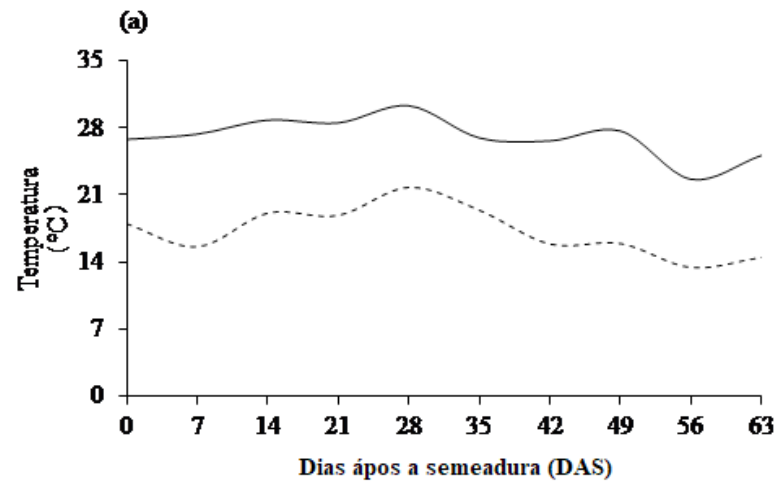

Foram utilizadas sementes de feijão, cultivar BRS Embaixador (Feijão comum com classificação comercial Vermelho escuro) com ciclo aproximado de 75-85 dias da semeadura até a maturação completa, sendo semeadas em 22/01/2013 em vasos de polietileno de 20 litros, para que se conseguisse obter três plantas em cada, perfazendo 80 vasos no total, com 20 vasos para cada concentração ácido giberélico. Os mesmos foram preenchidos com solo do horizonte A1 de um Planossolo Háplico Eutrófico Solódico, pertencente à unidade de mapeamento Pelotas (Streck et al., 2008), previamente corrigido, de acordo com análise prévia do solo e baseado no Manual de Adubação (CQFS RS/ SC, 2004).

Quando as plantas estavam no estádio V2, cerca de 7 dias após a semeadura, correspondente ao de folhas primárias totalmente abertas de acordo com a escala fenológica descrita por CIAT (1983), foi realizada a aplicação do ácido giberélico $\left(\mathrm{GA}_{3}\right)$

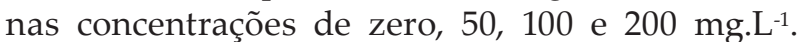
A aplicação foi realizada via foliar e por meio de pulverizador de barras pressurizado com $\mathrm{CO}_{2} \mathrm{com}$ pressão de $200 \mathrm{kPa}$ e pontas tipo leque (110-020), com volume de calda de 50 L.ha $^{-1}$. Preparou-se a calda de pulverização para 20 vasos, correspondente a cada concentração, baseado na área de cada vaso. A colheita das sementes para os teste de qualidade física e fisiológica foi realizada aos 80 dias após a semeadura daquelas plantas que não foram utilizadas para análise de crescimento.

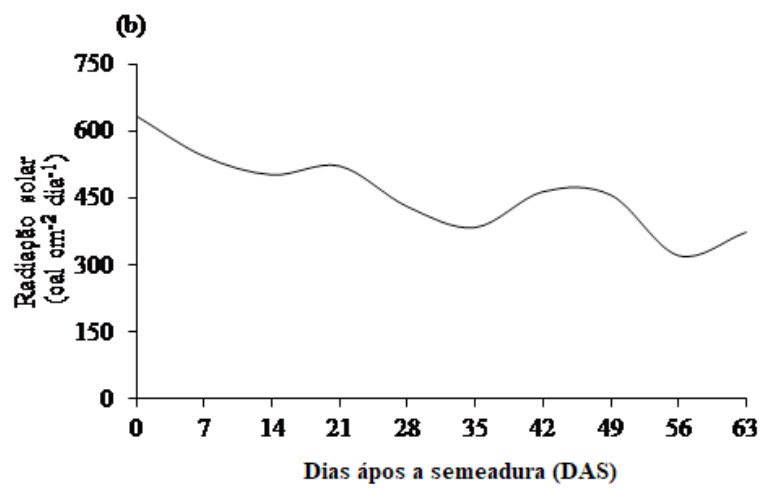

Figura 1 - Temperaturas máxima (___ e mínima (......) (a), radiação solar (b) durante o período de condução do experimento. 
O experimento foi realizado em duas etapas:

\section{Análise de crescimento}

As avaliações foram efetuadas por meio de coletas sucessivas, em intervalos regulares de tempo. As coletas iniciaram aos sete dias após a semeadura (DAS), sendo efetuados a cada sete dias, durante um período de 63 dias quando as plantas atingiram o estádio R9 de acordo com a escala fenológica de CIAT (1983). Em cada coleta, as plantas foram retiradas do solo e separadas em órgãos (folhas, caule, raízes e vagens) e acondicionadas, separadamente, em envelopes de papel pardo. Para a obtenção da matéria seca, o material foi transferido para estufa de ventilação forçada à temperatura de $70 \pm 2^{\circ} \mathrm{C}$, por 72 horas.

A área foliar $\left(\mathrm{A}_{\mathrm{f}}\right)$ foi determinada com o medidor de área marca Licor, modelo LI-3100 e índice de área foliar $(\mathrm{L})$ calculado pela fórmula $\mathrm{L}=\mathrm{A}_{\mathrm{f}} / \mathrm{S}_{\mathrm{t}^{\prime}}$ sendo $S_{t}$ a superfície do solo. Os dados primários de matéria seca total $\left(\mathrm{W}_{\mathrm{t}}\right)$ foram ajustados pela equação logística simples que é expressa por $\mathrm{W}_{\mathrm{t}}=$ $\mathrm{W}_{\mathrm{m}} /\left(1+\mathrm{A} \mathrm{e}^{-\mathrm{Bt}}\right)$, sendo $\mathrm{W}_{\mathrm{m}}$ a estimativa assintótica do crescimento máximo, A e B constantes de ajustamento, "e" a base do logaritmo neperiano e t o tempo em dias após a semeadura (Richards, 1969). Os dados primários de $\mathrm{A}_{\mathrm{f}}$ foram ajustados por meio de polinômios ortogonais (Richards, 1969). Os valores instantâneos da taxa de produção de matéria seca $\left(\mathrm{C}_{\mathrm{t}}\right)$ e taxa de crescimento de área foliar $\left(C_{2}\right)$ foram obtidos por meio de derivadas das equações ajustadas de $W_{t}$ e $A_{f}$ em relação ao tempo (Radford, 1967).

Para determinação do valor instantâneo da taxa de crescimento relativo $\left(\mathrm{R}_{\mathrm{w}}\right)$ foi empregada à equação: $\mathrm{R}_{\mathrm{w}}=1 / \mathrm{W}_{\mathrm{t}}$. dW/dt. Os valores instantâneos da taxa assimilatória líquida $\left(\mathrm{E}_{\mathrm{a}}\right)$, razão de área foliar $\left(\mathrm{F}_{\mathrm{a}}\right)$, razão de massa foliar $\left(\mathrm{F}_{\mathrm{w}}\right)$ e área foliar específica $\left(S_{a}\right)$ foram estimados por meio das equacões: $E_{a}=1 /$ $\mathrm{A}_{\mathrm{f}} \cdot \mathrm{dW} / \mathrm{dt} ; \mathrm{F}_{\mathrm{a}}=\mathrm{A}_{\mathrm{f}} / \mathrm{W}_{\mathrm{t}} ; \mathrm{F}_{\mathrm{w}}=\mathrm{W}_{\mathrm{f}} / \mathrm{W}_{\mathrm{t}}$ e $\mathrm{S}_{\mathrm{a}}=\mathrm{A}_{\mathrm{f}} / \mathrm{W}_{\mathrm{f}}$ conforme Radford (1967).

A eficiência de conversão da energia solar $(\xi)$ foi determinada pela equação $\xi(\%)=\left(100 . C_{t} \cdot \delta\right) / R_{a}$, sendo o $R_{a} o$ valor médio da radiação solar incidente (cal $\mathrm{m}^{-2}$ dia $\left.^{-1}\right)$ registrada nos quatorze dias anteriores ao $\mathrm{C}_{\mathrm{t}}$ correspondente e o valor calorífico (ठ) de $3800 \mathrm{cal} \mathrm{g}^{-1}$ citado por Cuesta et al. (1995). O índice de colheita $\left(\mathrm{H}_{\mathrm{i}}\right)$ foi determinado pela equação $\mathrm{H}_{\mathrm{i}}=\mathrm{W}_{\mathrm{vg}} / \mathrm{W}_{\mathrm{t}^{\prime}}$ sendo $W_{v g}$ a massa seca de vagens e $W_{t}$ a matéria seca total da planta. A partição de matéria seca entre as diferentes estruturas da planta (raízes, caule, folhas e vagens) ao longo do desenvolvimento das plantas foram determinados, separadamente, a partir da aferição da massa alocada em cada estrutura vegetal seguida pela transformação dos dados primários de alocação de massa seca de cada órgão para porcentagem.

\section{Determinação da qualidade física e fisiológica das sementes produzidas}

A massa de mil sementes (M1000) foi avaliada pelo emprego de oito repetições de 100 sementes, com umidade de 10\% (Brasil, 2009). O número de sementes por planta foi determinado por contagem direta e a altura da inserção da primeira vagem, obtida pelo comprimento desde a base do solo até a inserção da vagem no caule e os resultados expressos em centímetros.

O vigor das sementes produzidas foi avaliado pelo teste de comprimento de plântulas, realizado com quatro subamostras de 20 sementes, para cada tratamento. A semeadura foi efetuada sobre uma linha horizontal traçada no terço superior do papel de germinação do tipo "germitest", umedecidas com água destilada em quantidade de 2,5 vezes a massa seca do papel. Os rolos contendo as sementes permaneceram em câmara de germinação do tipo B.O.D. (Biochemical Oxygen Demand) por quatro dias a $25^{\circ} \mathrm{C}$, quando então se procedeu a avaliação, conforme descrito por Nakagawa (1999). A partir de quatro amostras de 10 plântulas para cada tratamento, determinou-se o comprimento de parte aérea e da raiz primária das plântulas, bem como a massa seca. O comprimento de parte aérea $\left(C_{P A}\right)$ foi obtido pela medida da distância entre a inserção da porção basal da raiz primária ao ápice da parte aérea, enquanto, o comprimento de radícula $\left(C_{R}\right)$ foi determinado pela medida da distância entre a parte apical e basal da raiz primária. Os resultados foram expressos em milímetros. Para a determinação da massa seca de parte aérea $\left(\mathrm{W}_{\mathrm{PA}}\right)$ e das raízes das plântulas $\left(W_{R}\right)$, as mesmas foram acondicionadas em envelopes de papel pardo e submetidas à secagem em estufa de ventilação 
forçada sob temperatura de $70 \pm 2^{\circ} \mathrm{C}$, por 72 horas. Os resultados foram expressos em gramas.

Para a análise de crescimento, o delineamento experimental utilizado foi inteiramente casualisado, sendo realizadas nove coletas de três plantas para cada concentração de $\mathrm{GA}_{3}$ e dia de coleta (DAS). Cada planta do vaso constituiu uma repetição, totalizando três repetições para cada concentração. Para os testes de qualidade física e fisiológica de sementes o delineamento utilizado foi inteiramente casualizado com quatro repetições.

Na primeira etapa, os dados primários de crescimento de área foliar e matéria seca foram submetidos à análise de variância a 5\% de probabilidade, sendo a matéria seca total analisada pela equação logística simples (Lopes e Lima, 2015), pelo fato da técnica de análise de crescimento não atender as pressuposições básicas da análise de variância, sendo modelo não aditivo e não linear. Além disso, na análise logística, os erros são correlacionados ao longo do tempo e assim não independentes (Dias e Barros, 2009). Neste sentido, por constituir-se em dados quantitativos, os dados de crescimento ao longo do desenvolvimento vegetal foram avaliados por meio de análise da tendência das curvas de crescimento (Radford, 1967; Barreiro et al., 2006) utilizando o ajuste do grau do polinômio para cada tendência. Dados de partição de assimilados foram convertidos em porcentagem de matéria seca alocada em cada estrutura vegetal. Na segunda etapa, os dados referentes a índice de colheita, massa de mil sementes, número de sementes por planta, inserção da primeira vagem, comprimento da parte aérea e raiz e massa seca da parte aérea e raiz foram submetidos à análise de variância, e no caso em que os valores de $\mathrm{F}$ foram significativos, aplicou-se o teste de Tukey a 5\% de probabilidade.

\section{RESULTADOS E DISCUSSÃO}

\section{Análise de crescimento}

O crescimento em termos de matéria seca total $\left(\mathrm{W}_{\mathrm{t}}\right)$ das plantas de feijão foi lento no início do ciclo de desenvolvimento até aproximadamente 21 DAS e seguido por período de intensa alocação de matéria seca até a última coleta, 63 DAS (Figura 2a). A partir dos 42 DAS, nota-se, uma superioridade de $W_{t}$ nas plantas de feijão que foram submetidas à aplicação exógena de $\mathrm{GA}_{3}$ em comparação com aquelas que não receberam, sendo que aos $63 \mathrm{DAS}$ apresentaram superioridade mínima de 18, 23 e $26 \%$ para as concentrações de 200,100 e $50 \mathrm{mg} \cdot \mathrm{L}^{-1}$ de $\mathrm{GA}_{3}$, respectivamente, em comparação àquelas que não foram submetidas à aplicação de $\mathrm{GA}_{3}$.

As taxas de produção de matéria seca $\left(C_{t}\right)$ atingiram valores máximos aproximadamente aos 35 DAS para plantas não submetidas à aplicação exógena de $\mathrm{GA}_{3}$ e à aplicação de $200 \mathrm{mg}$. $\mathrm{L}^{-1}$ (Figura $2 b$ ) valores que corroboram com os valores de Wt que foram alta em tal período (Figura 2a). Houve indicativo de atraso de aproximadamente sete dias para a obtenção das máximas $C_{t}$ ao avaliar de forma comparativa plantas submetidas a 50 e $100 \mathrm{mg} . \mathrm{L}^{-1}$ do produto comparativamente àquelas onde não houve aplicação de $\mathrm{GA}_{3}$.

O aumento na taxa de produção de matéria seca refere-se ao incremento da área de folhas disponíveis à captação de energia radiante, bem como, ao aumento na absorção de água e minerais. Por outro lado, a redução das taxas de produção de matéria seca relaciona-se à elevação do autossombreamento $\mathrm{e}$, posteriormente, à quantidade de tecidos não fotossintetizantes (Pedó et al., 2015). Além disso, o incremento e a redução da taxa de produção de matéria seca mantêm relação com a disponibilidade de temperatura e radiação solar disponíveis (Figura 1a e 1b), pois a qualidade das mesmas estão diretamente relacionadas com a fotossíntese e consequentemente com o acúmulo de matéria seca das plantas (Lopes e Lima, 2015).

As taxas de crescimento relativo $\left(\mathrm{R}_{\mathrm{w}}\right)$ foram inferiores até cerca de $28 \mathrm{DAS}$, em plantas submetidas às doses de 50 e 100 mg. $\mathrm{L}^{-1}$ de $\mathrm{GA}_{3}$ comparativamente àquelas sob influência da aplicação de $200 \mathrm{mg} \cdot \mathrm{L}^{-1}$ e àquelas que não foram submetidas à aplicação de $\mathrm{GA}_{3}$ (Figura 2c). Houve inversão nos valores de $\mathrm{R}_{\mathrm{w}^{\prime}}$ a partir dos $35 \mathrm{DAS}$, nas plantas submetidas às doses de 50 e $100 \mathrm{mg} . \mathrm{L}^{-1}$ de $\mathrm{GA}_{3}$ que apresentaram valores de $R_{w}$ de 0,0708 e $0,0657 \mathrm{~g} \mathrm{~g}^{-1} \mathrm{~d}^{-1}$, respectivamente. Neste sentido, as plantas que receberam as concentrações de $50 \mathrm{mg} . \mathrm{L}^{-1}$ e $100 \mathrm{mg} . \mathrm{L}^{-1}$ de $\mathrm{GA}_{3}$ apresentaram maior quantidade de matéria seca alocada em relação àquela pré-existente comparativamente às plantas sob influência de $200 \mathrm{mg} . \mathrm{L}^{-1} \mathrm{ou}$ àquelas não submetidas ao produto. Cabe destacar 
que o ácido giberélico possui efeito positivo no desempenho de plantas, contudo, apresenta ação negativa quando são empregadas altas concentrações (Dhakal e Erdei, 1986). A taxa de produção de matéria seca, que se equivale à taxa de crescimento da cultura, é aumentada pela aplicação de ácido giberélico quando a adubação nitrogenada está equilibrada (Khan et al., 2002).

Foram verificados dois picos de taxa assimilatória líquida $\left(\mathrm{E}_{\mathrm{a}}\right)$, tendo o primeiro ocorrido aos 7 DAS, em todos os tratamentos (Figura 2d). O segundo pico ocorreu aos 35 DAS em plantas submetidas a 50 e 200 mg.L-1 de $\mathrm{GA}_{3}$, sendo a maior $\mathrm{E}_{\mathrm{a}}$ observada na menor concentração do regulador de crescimento. Para plantas sob aplicação de $100 \mathrm{mg} \cdot \mathrm{L}^{-1}$ de $\mathrm{GA}_{3}$, o ponto de máxima resposta $\mathrm{E}_{\mathrm{a}}$ ocorreu aos 42 DAS, enquanto que, em plantas não submetidas à aplicação de $\mathrm{GA}_{3}$ a máxima $\mathrm{E}_{\mathrm{a}}$ foi obtida entre 35 e 42 DAS. Neste sentido, a aplicação de 50 e $200 \mathrm{mg} . \mathrm{L}^{-1}$ resultou em maior quantidade de assimilados produzidos por uma menor ou similar quantidade de folhas de plantas das demais doses.

No início do desenvolvimento das plantas a ocorrência de um primeiro pico de $E_{a}$ deve-se ao elevado número de folhas jovens com alta capacidade de síntese de assimilados, enquanto, o segundo pico de $\mathrm{E}_{\mathrm{a}}$ se deve ao surgimento dos órgãos reprodutivos que demandam elevada quantidade de assimilados (Lopes e Lima, 2015). Além disso, a elevação das taxas assimilatórias líquidas mantém relação com a área de folhas disponíveis à captação de energia luminosa, sendo os maiores valores de índice de área foliar para as concentrações de $\mathrm{GA}_{3}$ de 50 e $200 \mathrm{mg} \cdot \mathrm{L}^{-1}$ corroborando com os resultados de $\mathrm{E}_{\mathrm{a}}$ (Figura 2e).

O índice de área foliar (L) ajustou-se ao modelo quadrático com alto grau de significância (Figura 2e). Ocorreu maior L em plantas submetidas às doses de 50, 200 e $100 \mathrm{mg}^{-L^{-1}}$ de $\mathrm{GA}_{3}$, respectivamente, indicando maior área de solo coberta por folhas (Pedó et al., 2015) nas plantas submetidas à aplicação de $\mathrm{GA}_{3}$. Percebe-se que a aplicação do $\mathrm{GA}_{3}$ influenciou de forma positiva no incremento da área de folhas, obtendo o melhor resultado na dose de $50 \mathrm{mg} . \mathrm{L}^{-1}$, fato que pode ter ocorrido, pelo aumento do número e pela expansão das folhas. O aumento da área foliar resulta no autossombreamento, consequentemente, na redução das taxas de crescimento (Figura $2 \mathrm{~b}$ e $2 \mathrm{c}$ ).
A aplicação de $\mathrm{GA}_{3}$ promove o alongamento e a divisão celular, processos importantes para melhorar a altura e área foliar da planta (Arteca, 1996). Além disso, o aumento da permeabilidade da membrana celular pode facilitar a absorção e a utilização de nutrientes minerais e o transporte de assimilados o que, consequentemente, pode contribuir para melhorar a produção de biomassa (Figura 2a).

Em relação à razão de massa foliar $\left(\mathrm{F}_{\mathrm{w}}\right)$ houve, no geral, declínio a partir dos 21 DAS (Figura 2f). Plantas não submetida à aplicação de $\mathrm{GA}_{3}$ apresentaram superioridade na alocação de matéria seca nos limbos foliares, havendo, aos 63 DAS, a superioridade mínima de 22,2, 16,5 e 17,3\% comparativamente às plantas que receberam aplicação de 50, 100 e $200 \mathrm{mg} \cdot \mathrm{L}^{-1}$ do $\mathrm{GA}_{3}$, respectivamente. $\mathrm{O}$ aumento de $\mathrm{F}_{\mathrm{w}}$ no início do ciclo de desenvolvimento reflete a maior alocação de assimilados para as folhas em desenvolvimento, indicando este como o dreno metabólico preferencial. Por outro lado, a redução de $\mathrm{F}_{\mathrm{w}}$ ao longo do ciclo vegetal está relacionada à modificação do depósito metabólico preferencial para o colmo. Posteriormente, com o início da formação das vagens, ocorre novamente mudança no investimento preferencial de assimilados, passando para esta parte de modo acentuado e definitivo (Lopes e Lima, 2015).

A razão de área foliar $\left(\mathrm{F}_{\mathrm{a}}\right)$ atingiu maiores valores no início do desenvolvimento das plantas de feijão, sendo que o pico de $\mathrm{F}_{\mathrm{a}}$ para plantas submetidas a $50 \mathrm{mg} . \mathrm{L}^{-1}$ de $\mathrm{GA}_{3}$ foi aos 7 DAS e para as demais concentrações o mesmo aconteceu aos 14 DAS com posterior tendência ao decréscimo até os 63 DAS (Figura 3a). Plantas submetidas à aplicação de $50 \mathrm{mg}$. $\mathrm{L}^{-1}$ de ácido giberélico apresentaram maior $\mathrm{F}_{\mathrm{a}^{\prime}}$ sendo que, aos 28 DAS, houve superioridade de $21 \%$ em relação às plantas sem aplicação de $\mathrm{GA}_{3}$. Plantas sob influência da aplicação exógena de ácido giberélico demonstraram superioridade em relação à área de folhas úteis ao processo fotossintético, especialmente quando foi aplicado a concentração de $100 \mathrm{mg} . \mathrm{L}^{-1}$.

Os maiores valores de $F_{a}$ no início do ciclo de desenvolvimento corresponde à maior parte dos assimilados originados da fotossíntese serem direcionados para a formação de folhas (Aumonde et al., 2011a), sendo estes, os drenos metabólicos 
(a)

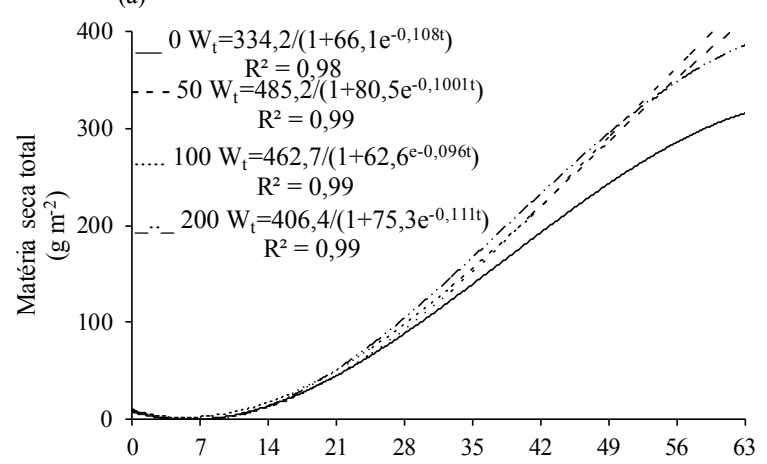

(c)

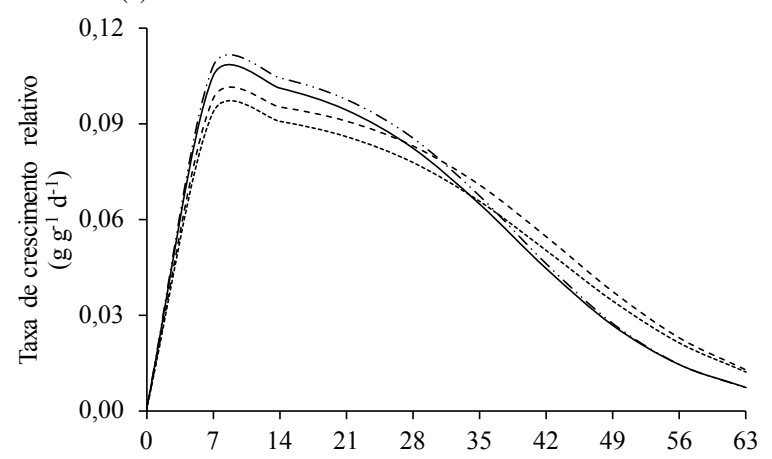

(e)

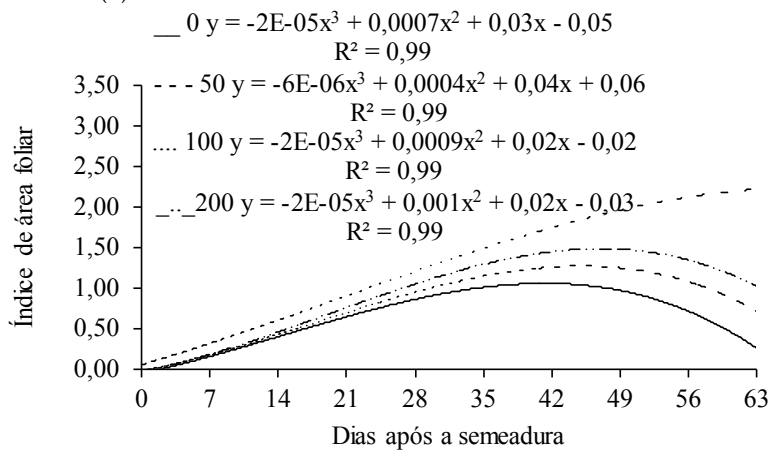

(b)

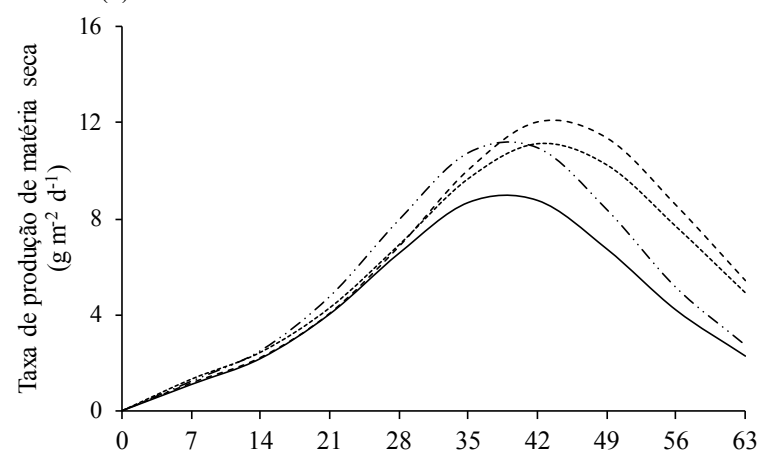

(d)
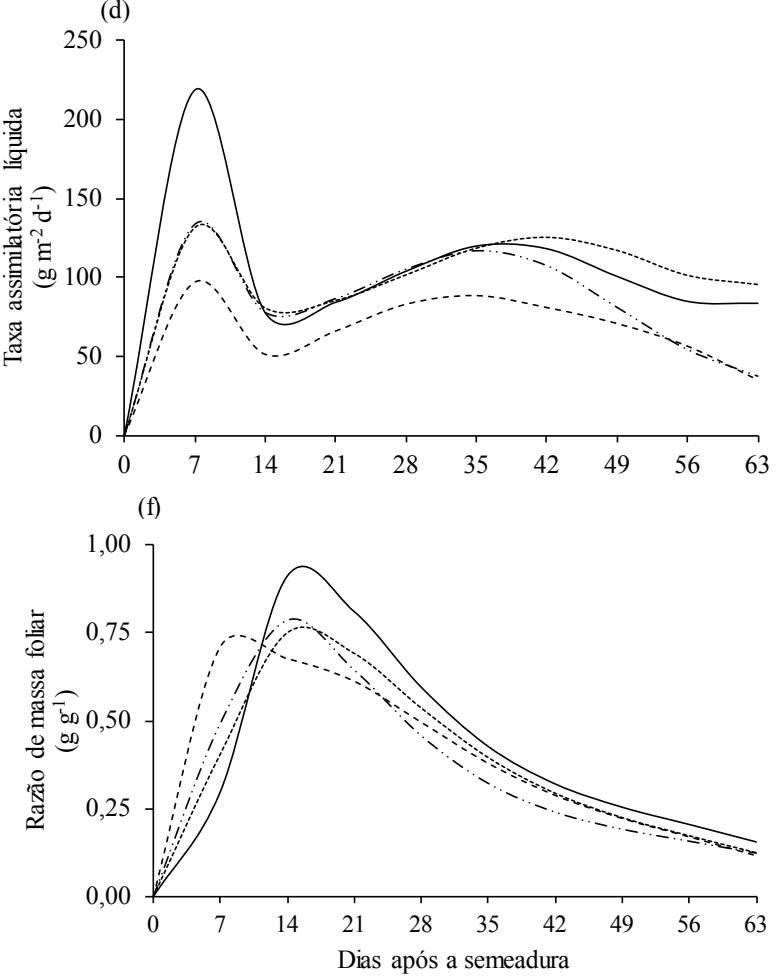

Figura 2 - $W_{t}(a), C_{t}(b), R_{w}(c), E_{a}(d), L(e)$ e $F_{w}$ (f) de plantas de feijão ao longo do desenvolvimento sob a influência da aplicação exógena de $\mathrm{GA}_{3}$. Sendo: zero (_.), 50 (_ _ _), 100 (.......) e 200 (_...) mg.L-1' de $\mathrm{GA}_{3}$

preferenciais neste período (Silva et al., 2007). No entanto, o decréscimo de $\mathrm{F}_{\mathrm{a}}$ no decorrer do ciclo das plantas pode ser explicado pelo aumento gradual de tecidos não assimilatórios e pela formação de estruturas reprodutivas que passam a constituir o dreno metabólico preferencial (Pedó et al., 2013). Nesta lógica, a menor $\mathrm{F}_{\mathrm{a}}$ indica a redução da área útil de folhas disponíveis ao processo fotossintético, fato que colaborou de forma mais pronunciada para as menores $W_{t}$ e $C_{t}$ obtidas por plantas que não receberam aplicação exógena de $\mathrm{GA}_{3}$ (Figura 2a e 2b).
A área foliar específica $\left(\mathrm{S}_{\mathrm{a}}\right)$ foi superior em plantas submetidas às doses de 50, 200 e 100 mg.L-1 de GA respectivamente, comparativamente àquelas não submetidas à aplicação do referido regulador de crescimento (Figura 3b). Ocorreu diferença mais expressiva a partir dos 42 DAS para as plantas submetidas à aplicação de 50 e de $200 \mathrm{mg} . \mathrm{L}^{-1}$ de $\mathrm{GA}_{3}$, apresentando superioridade de 39 e $34 \%$, respectivamente, comparativamente àquelas em que não houve aplicação do produto. Sendo assim, verificou-se que plantas sob a ação do $\mathrm{GA}_{3}$ apresentaram folhas com menor espessura relativamente àquelas não submetidas à aplicação. 
As taxas de crescimento relativo de área foliar $\left(\mathrm{C}_{\mathrm{a}}\right)$ elevaram-se até os 35 DAS em plantas sob aplicação de $50 \mathrm{mg} . \mathrm{L}^{-1}$ de $\mathrm{GA}_{3}$ e até 42 DAS para plantas das demais concentrações, com posterior tendência ao decréscimo (Figura 3c). Ocorreu atraso temporal de sete dias no valor de $C_{a}$ ao submeter às plantas de feijão à concentração de $50 \mathrm{mg}$.L-1 de GA $\mathrm{G}_{3}$. É possível inferir que plantas sob influência do produto, especialmente na concentração de 50 mg.L-1 atingiram superior capacidade de aumentar a matéria seca de folha em relação à matéria que as folhas possuíam inicialmente (Figura $2 b$ ), colaborando para a obtenção da superior área foliar em plantas deste tratamento (Figura 2e).

A eficiência de conversão de energia solar $(\xi)$ foi máxima aos 35 DAS para plantas de todas as doses, com posterior tendência de redução em plantas não submetidas à aplicação de $\mathrm{GA}_{3}$ ou sob aplicação de 200 mg.L L $^{-1}$ (Figura 3d). Plantas submetidas às doses de 50 e 100 mg. $\mathrm{L}^{-1}$ apresentaram um segundo pico de $\xi$ aos 56 DAS, demonstrando superioridade de 51 e $45 \%$, respectivamente, em relação às plantas que não foram submetidas à aplicação de $\mathrm{GA}_{3}$. $\mathrm{O}$ aumento constatado para $\xi$ corrobora com a tendência observada para $C_{t}$ (Figura $2 b$ ) e para a radiação solar (Figura 1b).

A eficiência de captação e de utilização da radiação solar é dependente do número de folhas do dossel, o tamanho e da velocidade de crescimento das folhas, assim como, como da arquitetura da planta. A $\xi$ mantém relação ao índice de área foliar e ao ângulo de inserção das folhas e com o acúmulo de biomassa sendo observado na dose de $50 \mathrm{mg}$. $\mathrm{L}^{-1}$ que obteve a maior $\xi$ assim como maior L. Desse modo, a adequada arquitetura da planta contribui substancialmente para o aumento no índice de colheita, ao maximizar a área de captação e absorção de energia solar (Zhu et al., 2010).

A partição de matéria seca entre as diferentes estruturas das plantas de feijão comportou-se de forma similar para todas as concentrações de $\mathrm{GA}_{3}$ (Figura 4a, 4b, 4c e 4d). Analisando a distribuição de assimilados o acúmulo de matéria seca nas (a)

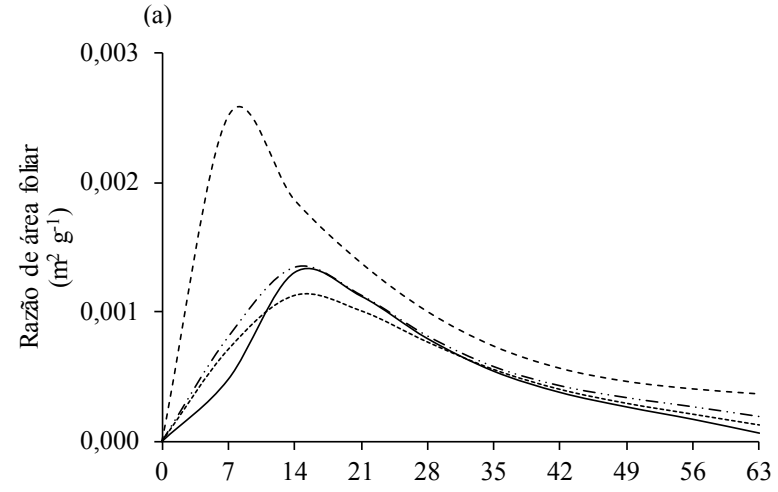

(c)

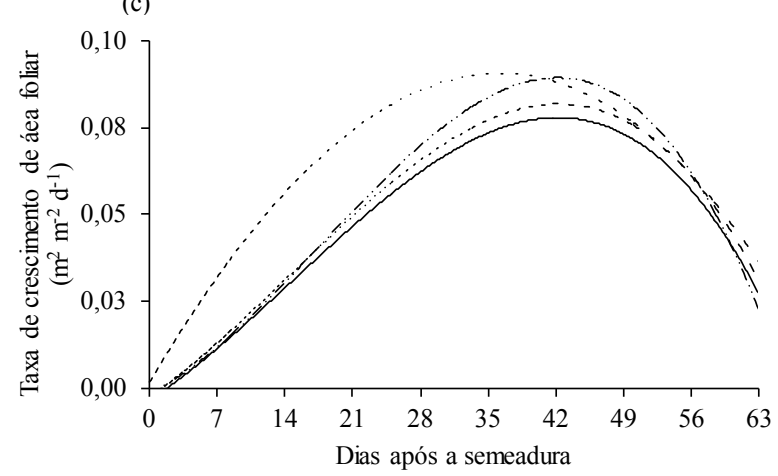

(b)
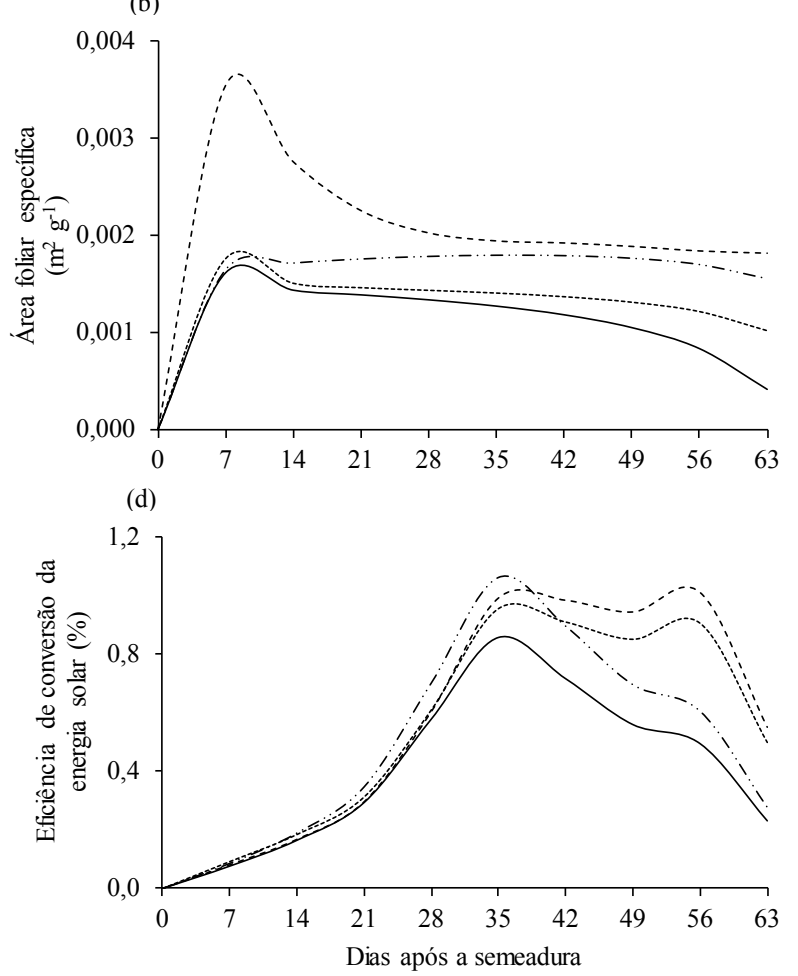

Figura 3 - Fa (a), Sa (b), Ca (c) e $\xi(d)$ em plantas de feijão ao longo do desenvolvimento sob influência de concentrações exógenas de $\mathrm{GA}_{3}$. Sendo: zero (__), 50 (_ _ _), 100 (......) e 200 (_.._) mg.L-1 de $\mathrm{GA}_{3}$. 
(a)

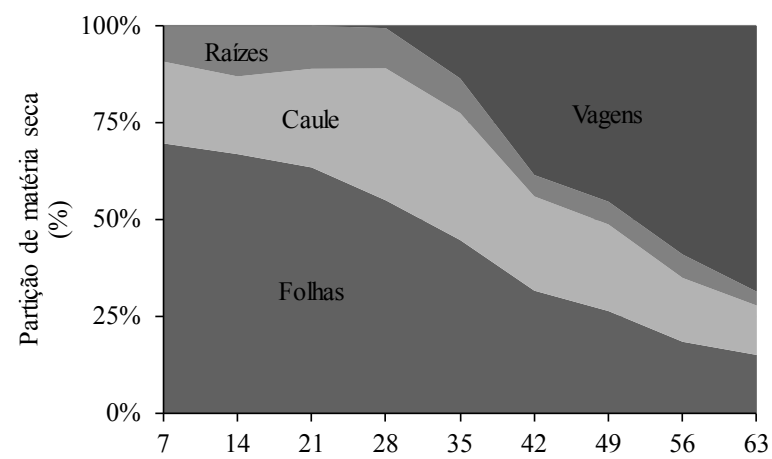

(c)

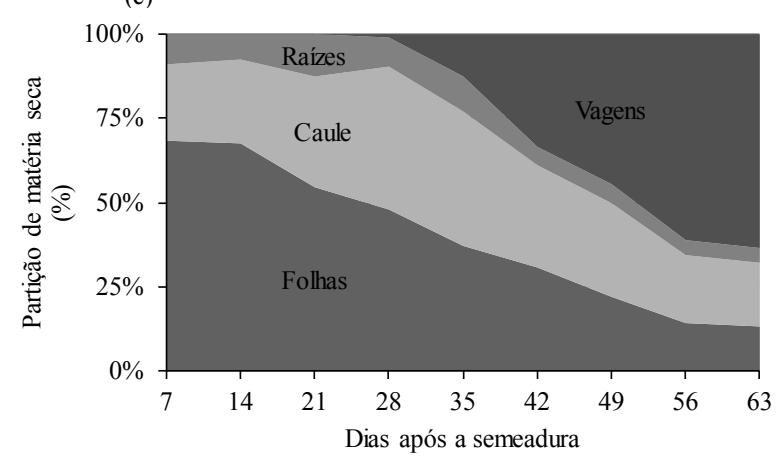

(b)

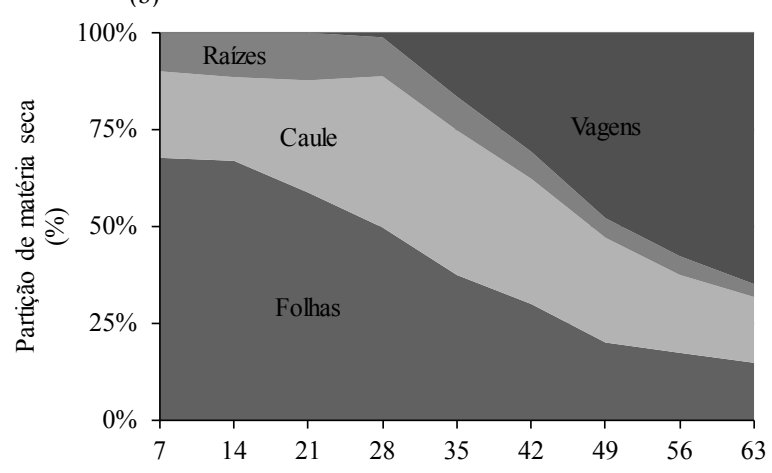

(d)

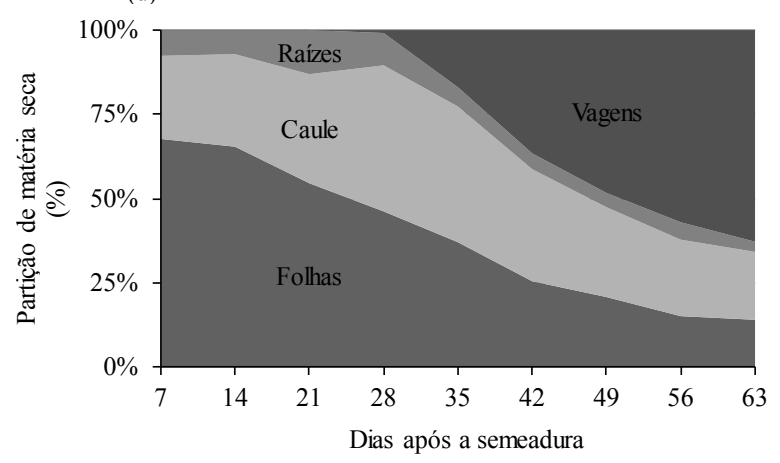

Figura 4 - Partição de matéria seca em plantas de feijão ao longo do desenvolvimento sob influência de concentrações exógenas de ácido giberélico. Sendo: zero (a), 50 (b), 100 (c) e 200 (d) mg.L-1 de GA.

folhas foi crescente até os 28 DAS para plantas de feijão submetidas a todas as concentrações, sendo a quantidade máxima acumulada em relação à matéria seca total de $54,9,49,7,48,0$ e $46,2 \%$ para as concentrações de zero 50, 100 e $200 \mathrm{mg} \cdot \mathrm{L}^{-1} \mathrm{de}$ $\mathrm{GA}_{3}$, respectivamente. A matéria seca do caule de maneira similar a matéria seca de folhas foi crescente para todas as concentrações até os 28 DAS, sendo a maior matéria seca do caule em relação à matéria seca total para a concentração de $200 \mathrm{mg} . \mathrm{L}^{-1}$. Portanto, a partir de 42 DAS houve alteração do dreno metabólico com a formação de vagens, passando a importar mais assimilados para as sementes, ocasionando redução na partição de matéria seca nas demais estruturas (Aumonde et al., 2011b). Aos 63 DAS à matéria seca de vagens em relação à matéria seca total foi maior nas concentrações de zero 100, 200 e 50 mg.L-1, respectivamente (Figura 4a, 4b, 4c e 4d).

O reduzido crescimento na fase inicial do desenvolvimento, é comum em diversas espécies vegetais e pode ser explicado pelo reduzido volume de raízes e pela baixa absorção de água e de minerais, pela pequena área foliar e pela reduzida taxa de respiração e taxa assimilatória líquida (Aumonde et al., 2011a). No início do ciclo, as folhas se comportaram como fonte-dreno, uma vez que é responsável pela produção de fotoassimilados e também o órgão com maior armazenamento de compostos (Lopes et al., 2011). Em estádio mais avançado, com o surgimento das sementes cedem lugar para estas unidades de perpetuação da espécie que representam o dreno metabólico preferencial e definitivo enquanto raízes, caules e folhas utilizam assimilados provenientes do processo fotossintético em menor intensidade com vistas a manutenção estrutural da planta (Lopes e Lima, 2015).

\section{Qualidade física e fisiológica das sementes produzidas}

O índice de colheita $\left(\mathrm{H}_{\mathrm{i}}\right)$ apresentou diferenças significativas nas diferentes concentrações de $\mathrm{GA}_{3}$ (Quadro 1). Houve uma superioridade para 
$\mathrm{H}_{\mathrm{i}}$ quando as plantas não foram submetidas à aplicação de $\mathrm{GA}_{3}$, porém, sem diferir estatisticamente da concentração de $50 \mathrm{mg} \cdot \mathrm{L}^{-1}$. Houve uma tendência a redução nos valores de $\mathrm{H}_{\mathrm{i}}$ ao elevar a concentração de $\mathrm{GA}_{3}$ aplicado nas plantas até a dose de $200 \mathrm{mg} . \mathrm{L}^{-1}$ no entanto, estatisticamente esses valores não diferiram das concentrações de 50 e $100 \mathrm{mg} . \mathrm{L}^{-1}$. A redução do índice de colheita com o aumento da concentração de $\mathrm{GA}_{3}$ permite inferir que plantas submetidas às maiores doses de $\mathrm{GA}_{3}$, apresentam menor alocação de carbono em sementes em relação à matéria seca total alocada na planta, fato que pode estar relacionado com o potencial fisiológico das sementes e pode prejudicar a produtividade da cultura do feijão.

A inserção da primeira vagem (IPv) foi modificada com a aplicação das diferentes concentrações de $\mathrm{GA}_{3}$ (Quadro 1). A IPv foi superior para a concentração de $200 \mathrm{mg}^{-\mathrm{L}^{-1}}$ de $\mathrm{GA}_{3}$, porém, sem diferir estatisticamente da concentração de $100 \mathrm{mg} \cdot \mathrm{L}^{-1}$. Houve um incremento na altura da IPv na concentração de 200 e $100 \mathrm{mg} . \mathrm{L}^{-1}$ de 41 e $38 \%$, respectivamente, em relação as plantas de feijão de que não receberam $\mathrm{GA}_{3}$. Logo, a aplicação de $100 \mathrm{e}$ $200 \mathrm{mg} . \mathrm{L}^{-1}$ pode favorecer a colheita mecânica e constituir fator importante frente a mecanização do seu cultivo, contudo, rendimento produtivo de plantas de feijão pode ser afetado negativamente. Segundo Pereira et al. (2004) as giberelinas, estão envolvidas na atividade cambial, estimulando o elongamento caulinar, a divisão e elongamento celular. Resultados similares ao presente estudo foram encontrados em soja por Leite et al. (2003) com aumento da estatura dos entrenós da haste e em feijão (Souza et al., 2010b) obtendo aumento da haste e detrimento do diâmetro médio do hipocótilo e epicótilo.

O número de sementes por planta (NSp) foi reduzido conforme aumentou a concentração de $\mathrm{GA}_{3}$ colaborando para a redução do índice de colheita (Quadro 1). A superioridade no NSp foi na ordem de $33 \%$ em plantas que não foram submetidas a aplicação de $\mathrm{GA}_{3}$ comparativamente aquelas sob aplicação de $200 \mathrm{mg} \cdot \mathrm{L}^{-1}$.

A massa de mil sementes (M1000) foi superior quando as plantas foram submetidas a concentração de $50 \mathrm{mg} . \mathrm{L}^{-1} \mathrm{sem}$ no entanto diferir estatisticamente das doses de 100 e 200 mg.L ${ }^{-1}$. Houve uma inferioridade na M1000 quando as plantas não foram submetidas à aplicação de $\mathrm{GA}_{3}$, porém, não houve diferenças estatísticas entre a referida e

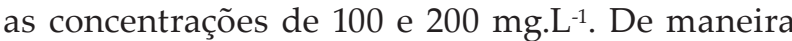
geral nota-se que plantas de feijão submetidas à aplicação de $\mathrm{GA}_{3}$ modificam a M1000. Isto porque, plantas submetidas as referidas concentrações do produto atingiram conjuntamente um maior nível de matéria seca total alocada (Figura 2a), favorecendo a redução do índice de colheita (Quadro 1). A redução do número de sementes por planta pode resultar na diminuição da massa seca da parte comercial produzida por planta. Os menores valores desta variável podem ser relacionados com a modificação na força do dreno, uma vez que, este atributo de crescimento estabelece a relação entre matéria seca da parte comercial e matéria seca total da planta (Benincasa, 2003).

A superioridade da M1000 em plantas que foram submetidas à aplicação de $\mathrm{GA}_{3}$ em relação as que não receberam aplicação demonstra que as sementes apresentaram superior qualidade física, podendo apresentar, desta forma, melhor formação (Peske et al., 2012). Sementes com maior M1000 evidenciam maior quantidade de assimilados e ajuste mais elaborado do sistema de membranas celulares ao receberem quantidades adequadas de oligossacarídeos da série rafinósica e de proteínas LEA, estando mais aptas ao processo de secagem artificial. Estas sementes, dentro de certos limites, tendem a originar plântulas mais vigorosas e com maior quantidade de massa seca (Bewley et al., 2013).

Ao avaliar a qualidade fisiológica e expressão do vigor das sementes produzidas pelo teste de comprimento de plântulas verifica-se que houve

Quadro 1 - Valores médios para $H_{i}$, IPv, NSp e M1000 de feijão submetidos a diferentes concentrações de $\mathrm{GA}_{3}$

\begin{tabular}{lcccc}
\hline Concentração de GA3 & $\mathbf{H}_{\mathbf{i}}$ & IPv (cm) & NSp & M1000 (g) \\
\hline 0 mg.L ${ }^{-1}$ & $0,69 \mathrm{a}$ & $21,2 \mathrm{c}$ & $24,6 \mathrm{a}$ & $458,9 \mathrm{~b}$ \\
$50 \mathrm{mg} \cdot \mathrm{L}^{-1}$ & $0,65 \mathrm{ab}$ & $30,6 \mathrm{~b}$ & $21,6 \mathrm{ab}$ & $476,7 \mathrm{a}$ \\
$100 \mathrm{mg} \cdot \mathrm{L}^{-1}$ & $0,64 \mathrm{~b}$ & $34,5 \mathrm{ab}$ & $18,4 \mathrm{ab}$ & $467,8 \mathrm{ab}$ \\
$200 \mathrm{mg} \cdot \mathrm{L}^{-1}$ & $0,63 \mathrm{~b}$ & $36,0 \mathrm{a}$ & $16,4 \mathrm{~b}$ & $462,3 \mathrm{ab}$ \\
\hline CV $(\%)$ & 7,6 & 13,7 & 28,6 & 3,0 \\
\hline
\end{tabular}

Valores com a mesma letra na coluna não diferem significativamente entre si pelo teste de Tukey a $5 \%$ de probabilidade. 
diferenças significativas para comprimento da parte aérea $\left(C_{P A}\right)$ raiz $\left(C_{R}\right)$ e massa seca de raiz $\left(W_{R}\right)$. Para massa seca da parte aérea $\left(\mathrm{W}_{\mathrm{PA}}\right)$ não se constatou diferenças significativas para as diferentes concentrações de $\mathrm{GA}_{3}$ (Quadro 2).

$O C_{P A}$ foi superior quando as plantas não foram submetidasàaplicaçãode $\mathrm{GA}_{3}$ sem, noentanto, diferir estatisticamente da concentração de $200 \mathrm{mg} \cdot \mathrm{L}^{-1}$. Para o comprimento da raiz $\left(C_{R}\right)$ o menor valor foi verificado na concentração de $50 \mathrm{mg} . \mathrm{L}^{-1}$ de $G_{3}$. De maneira similar a $C_{R}$, a $W_{R}$ foi menor na concentração de $50 \mathrm{mg} \cdot \mathrm{L}^{-1}$, contudo, a maior $W_{R}$ foi constatada na concentração de $100 \mathrm{mg} \cdot \mathrm{L}^{-1}$ de $\mathrm{GA}_{3}$ (Quadro 2). O aumento da M1000 quando se utilizou as diferentes concentrações de $\mathrm{GA}_{3}$ não correspondeu à superior alocação de matéria seca em plântulas, não colaborando para a superioridade em desempenho de crescimento inicial.

De maneira geral, este trabalho sugere uma opção a mais de tecnologia, que auxilie no aumento da eficiência de colheita mecanizada, por aumentar a inserção da primeira vagem nas doses de 100 e 200 mg.L-1. Também é um dos pioneiros na descrição da aplicação exógena de $\mathrm{GA}_{3}$ sobre as

Quadro 2 - Valores médias para $C_{P A}, C_{R}, W_{P A}$ e $W_{R}$ de plântulas de feijão oriundas de sementes produzidas sob diferentes concentrações de $\mathrm{GA}_{3}$

\begin{tabular}{lcccc}
\hline Concentração de GA3 & $\mathbf{C}_{\mathrm{PA}}(\mathrm{mm})$ & $\mathbf{C}_{\mathrm{R}}(\mathrm{mm})$ & $\mathbf{W}_{\mathrm{PA}}(\mathrm{g})$ & $\mathbf{W}_{\mathrm{R}}(\mathrm{g})$ \\
\hline $0 \mathrm{mg} \cdot \mathrm{L}^{-1}$ & $106,5 \mathrm{a}$ & $169,9 \mathrm{a}$ & $1,0 \mathrm{a}$ & $0,4 \mathrm{~b}$ \\
$50 \mathrm{mg} \cdot \mathrm{L}^{-1}$ & $98,5 \mathrm{~b}$ & $147,9 \mathrm{~b}$ & $0,9 \mathrm{a}$ & $0,3 \mathrm{c}$ \\
$100 \mathrm{mg} \cdot \mathrm{L}^{-1}$ & $97,8 \mathrm{~b}$ & $175,8 \mathrm{a}$ & $1,0 \mathrm{a}$ & $0,5 \mathrm{a}$ \\
$200 \mathrm{mg} \cdot \mathrm{L}^{-1}$ & $102,0 \mathrm{ab}$ & $171,1 \mathrm{a}$ & $0,9 \mathrm{a}$ & $0,4 \mathrm{~b}$ \\
\hline $\mathrm{CV}(\%)$ & 3,0 & 5,4 & 3,1 & 7,11 \\
\hline
\end{tabular}

Valores com a mesma letra na coluna não diferem significativamente entre si pelo teste de Tukey a $5 \%$ de probabilidade. plantas e seus efeitos no crescimento e qualidade das sementes produzidas. A aplicação exógena de ácido giberélico favoreceu algumas das características de crescimento de plantas de feijão, entre elas, o índice de área foliar, a área foliar específica, razão de área foliar, taxa de crescimento de área foliar na concentração de $50 \mathrm{mg} \cdot \mathrm{L}^{-1}$. O maior índice de área foliar pode ter colaborado para a obtenção dos maiores valores de matéria seca total e de taxa de produção de matéria seca, assim como, para a superior massa de mil sementes na dose de $50 \mathrm{mg} \cdot \mathrm{L}^{-1}$. Contudo, maiores concentração do produto, 100 e $200 \mathrm{mg} . \mathrm{L}^{-1}$ resultou em efeitos negativos no número de sementes por planta e no índice de colheita. Quando se trata de produção de sementes, a qualidade do produto produzido é mais importante do que a quantidade sendo então o $\mathrm{GA}_{3}$ uma estratégica benéfica para a cultura do feijão.

\section{CONCLUSÕES}

O crescimento de plantas de feijão é modificado de forma quantitativa e temporal pela aplicação exógena de $\mathrm{GA}_{3}$.

A aplicação exógena de $\mathrm{GA}_{3}$ pode ser uma alternativa para produção de sementes de feijão de melhor qualidade pelo fato de as mesma aumentarem a inserção da primeira vagem podendo facilitar a colheita mecanizada. Neste sentido, doses entre 100 e 200 mg. $\mathrm{L}^{-1}$ de $\mathrm{GA}_{3}$ são as mais indicadas para a cultura do feijão.

O índice de colheita é reduzido nas plantas ao elevar a concentração de $\mathrm{GA}_{3}$ até de $200 \mathrm{mg} \cdot \mathrm{L}^{-1}$, contudo a massa de mil sementes é maior em menores concentrações, o que revela que para esse caráter a melhor dose a ser aplicado é de $50 \mathrm{mg} . \mathrm{L}^{-1}$.

\section{REFERÊNCIAS BIBLIOGRÁFICAS}

Arteca, R.N. (1996) - Plant Growth Substances: Principles and Applications. New York, Chapman and Hall Inc, $331 \mathrm{p}$.

Aumonde, T.Z.; Lopes, N.F.; Moraes, D.M.; Peil, R.M.N. \& Pedó, T. (2011a) - Análise de crescimento do híbrido de mini melancia Smile® enxertada e não enxertada. Interciência, vol. 36, n. 9, p. 677-681.

Aumonde, T.Z.; Pedó, T.; Martinazzo, E.G.; Moraes, D.M.; Villela, F.A. \& Lopes, N.F. (2013) - Análise de crescimento e partição de assimilados em plantas de maria-pretinha submetidas a níveis de sombreamento. Planta Daninha, vol. 31, n. 1, p. 99-108. http://dx.doi.org/10.1590/S0100-83582013000100011 
Aumonde, T.Z.; Pedó, T.; Lopes, N.F.; Moraes, D.M. de \& Peil, R.M.N. (2011b) - Partição de matéria seca em plantas do híbrido de mini melancia Smile ${ }^{\circledR}$ enxertada e não enxertada. Revista Brasileira de Biociências, vol. 9, n. 3, p. 387-391.

Baldissera, J.N.R.; Valentini, G.; Coan, M.M.D.; Almeida, C.B.; Guidolin, A.F. \& Coimbra, J.L.M. (2012) Capacidade combinatória e efeito recíproco em características agronômicas do feijão. Semina: Ciências Agrárias, vol. 33, n. 2, p. 471-480. http://dx.doi.org/10.5433/1679-0359.2012v33n2p471

Barreiro, A.P.; Zucareli, A.; Ono, E.O. \& Rodrigues, J.D. (2006) - Análise de crescimento de plantas de manjericão. Bragantia, vol. 65, n. 4, p. 563-567.

Benincasa, M.M.P. (2003) - Análise de Crescimento de Plantas (noções básicas). Jaboticabal, Funep, 41 p.

Bewley, J.D.; Bradford, K.J.; Hilhorst, H.W.M. \& Nonogaki, H. (2013) - Seeds: Physiology of Development, Germination and Dormancy. $3^{\underline{a}}$ ed. New York, Springer-Verlag, 445 p.

Brasil (2009) - Regras para Análise de Sementes. Brasília: Secretaria de Defesa Agropecuária. Ministério da Agricultura e da Reforma Agrária. mapa/ACS, 399 p.

Buchanan, B.B.; Gruissem, W. \& Jones, R.L. (2015) - Biochemistry and molecular biology of plants. $2^{a}$ ed. Rockville, American Society of Plant Physiologists, 1280 p.

Carraher Jr., C.E.; Carraher, S.M. \& Stewart, H.H. (2010) - Metal-containing polymer structures for enhanced seed germination and plant growth. Advances in Environmental Biology, vol. 4, n. 1, p. 108-116.

Carvalho, N.M. \& Nakagawa, J. (2012) - Sementes: Ciência, tecnologia e produção. 5aㅡ ed. Jaboticabal, Funep, 590 p.

Cato, S.C. \& Castro, P.R.C. (2006) - Redução da altura de plantas de soja causada pelo ácido 2,3,5 triiodobenzóico. Ciência Rural, vol. 36, n. 3, p. 981-984. http://dx.doi.org/10.1590/S0103-84782006000300041

CIAT (1983) - Etapas de desarollo de la planta de frijol común. Cali, Colombia, CIAT, 26 p.

CQFS RS/SC (2004) - Manual de adubação e calagem para os estados do Rio Grande do Sul e Santa Catarina. Comissão de Química e Fertilidade do Solo ( rs/sc). 10åed. Porto Alegre, Sociedade Brasileira de Ciência do Solo/Núcleo Regional Sul, 400 p.

Correia, N.M. \& Leite, G.J. (2012) - Selectivity of the plant growth regulators trinexapac-ethyl and sulfometuron-methyl to cultivated species. Scientia Agricola, vol. 69, n. 3, p. 194-200. http://dx.doi.org/10.1590/ S0103-90162012000300004

Cuesta, R.R.; Lopes, N.F.; Oliva, M.A. \& Franco, A.A. (1995) - Crescimento e conversão da energia solar em Phaseolus vulgares L. em função da fonte de nitrogênio. Revista Ceres, vol. 42, n. 242, p. 405-422.

Dhakal, M.R. \& Erdei, L. (1986) - Long-term effects of plant hormones on $\mathrm{K}^{+}$levels and transport in young wheat plants of different $\mathrm{K}^{+}$status. Physiologia Plantarum, vol. 68, n. 4, p. 632-636. http://dx.doi. org/10.1111/j.1399-3054.1986.tb03408.x

Dias, L.A.S. \& Barros, W.S. (2009) - Biometria Experimental. 1ํㅡㄹ ed. Viçosa, Suprema Gráfica e Editora Ltda, $408 \mathrm{p}$.

Furlani, C.E.A.; Silva, R.P.; Filho, A.F.; Cortez, J.W. \& Grotta, D.C.C. (2008)-Semeadora-adubadora: exigências em função do preparo do solo, da pressão de inflação do pneu e da velocidade. Revista Brasileira de Ciência do Solo, vol. 32, n. 1, p. 345-352. http://dx.doi.org/10.1590/S0100-06832008000100032

Khan, N.A.; Mir, R.; Khan, M. \& Javid, S. (2002) - Effects of gibberellic acid spray on nitrogen yield efficiency of mustard grown with different nitrogen levels. Plant Growth Regulation, vol. 38, n. 3, p. 243-247. http:// dx.doi.org/10.1023/A:1021523707239

Lana, A.M.Q.; Lana, R.M.Q.; Gozuen, C.F.; Bonotto, I. \& Trevisan, L.R. (2009) - Aplicação de reguladores de crescimento na cultura do feijoeiro. Bioscience Journal, vol. 25, n. 1, p. 13-20.

Leite, V.M.; Rosolem, C.A. \& Rodrigues, J.D. (2003) - Gibberellin and cytokinin effects on soybean growth. Scientia Agricola, vol. 60, n. 3, p. 537-541. http://dx.doi.org/10.1590/S0103-90162003000300019

Lopes, N.F. \& Lima, M. da G.de S. (2015) - Fisiologia da produção. Viçosa, Minas Gerais, UFV, 492 p.

Lopes, W.A.R.; Negreiros, M.Z.; Dombroski, J.L.D.; Rodrigues, G.S.O.; Soares, A.M. \& Araújo, A.P. (2011) - Análise do crescimento de tomate 'SM-16' cultivado sob diferentes coberturas de solo. Horticultura Brasileira, vol. 29, n. 4, p. 554-561. http://dx.doi.org/10.1590/S0102-05362011000400019

Matos Filho, C.H.A.; Gomes, R.L.F.; Rocha, M.M.; Freire Filho, F.R. \& Almeida, A.C. (2009) - Potencial produtivo de progênies de feijão-caupi com arquitetura ereta de planta. Ciência Rural, vol. 39, n. 2, p. 348354. http://dx.doi.org/10.1590/S0103-84782009000200006 
Mir, M.R.; Mobin, M.; Khan, N.A.; Bhat, M.A.; Lone, N.A.; Bhat, K.A.; Razvi, S.M.; Wani, S.A.; Wani, N.; Akhter, S.; Rashid, S.; Masoodi, N.H. \& Payne, W.A. (2010) - Crop responses to interaction between plant growth regulators and nutrients. Journal of Phytology, vol. 2, n. 10, p. 9-19.

Nakagawa, J. (1999) - Testes de vigor baseados no desempenho de plântulas. In: Krzyzanowski, F.C.; Vieira, R.D. \& França Neto, J.B. (Eds.) - Vigor de sementes: conceitos e testes. Londrina, Abrates, p. 1-24.

Pavlista, A.D.; Schild, J.A.; Hergert, G.W. \& Urrea, C.A. (2006) - Early growth promotion of dry beans (Phaseolus vulgaris L.) by gibberellic acid. Bean Improvement Cooperative, vol. 49, n. 1, p. 93-94.

Pedó, T.; Aumonde, T.Z.; Lopes, N.F.; Villela, F.A. \& Mauch, C.R. (2013) - Análise comparativa de crescimento entre genótipos de pimenta cultivados em casa de vegetação. Bioscience Journal, vol. 29, n. 1, p. 125-131.

Pedó, T.; Koch, F.; Martinazzo, E. G.; Villela, F. A. \& Aumonde, T. Z. (2015) - Physiological attributes, growth and expression of vigor in soybean seeds under soil waterlogging. African Journal of Agricultural Research, vol. 10, n. 39, p. 3791-3797. http://dx.doi.org/10.5897/AJAR2015.9661

Pereira, J.E.S.; Fortes, G.R.L. \& Silva, J.B. (2001) - Crescimento de plantas micropropagadas de macieira em casa de vegetação com aplicações de ácido giberélico. Pesquisa Agropecuária Brasileira, vol. 36, n. 6, p. 881886. http://dx.doi.org/10.1590/S0100-204X2001000600005

Pereira, R.P.W.; Monteiro, M.B.de O. \& Abreu, H. dos S. (2004) - Os Fitohôrmonios na formação da madeira. Floresta e Ambiente, vol. 11, n. 2, p. 40-47.

Peske, S.T.; Villela, F.A. \& Meneguello, G.E. (2012) - Sementes: Fundamentos Científicos e Tecnológicos. 3ª ed. Pelotas, $573 \mathrm{p}$.

Rademacher, W. (2000) - Growth Retardants: effects on gibberellin biosynthesis and other metabolic pathways. Annual Review of Plant Physiology and Plant Molecular Biology, vol. 51, p. 501-531. https://doi. org/10.1146/annurev.arplant.51.1.501

Radford, P.J. (1967) - Growth analysis formulae: their use and abuse. Crop Science, vol. 7, n. 3, p. 171-175. https://doi.org/10.2135/cropsci1967.0011183X000700030001x

Richards, F.J. (1969) - The quantitative analysis of growth. In: Stewward, F.C. (Ed.) - Plant physiology. New York, Academic Press, p. 3-76.

Sartori, M.G.B. (2003) - A dinâmica do clima do Rio Grande do Sul: indução empírica e conhecimento científico. Terra Livre, vol. 1, n. 20, p. 27-49.

Silva, R.N. da; Lopes, N.F.; Duarte, G.L.; Moraes, D.M. de \& Pereira, A.L.A. (2007) - Análise de crescimento de plantas de Hordeum vulgare L. submetidas a estresse salino. Revista Brasileira de Agrociência, vol. 13, n. 4, p. 455-463.

Silva, R.P.; Reis, L.D.; Reis, G.N.; Furlani, C.E.A.; Lopes, A. \& Cortez, J.W. (2008) - Desempenho operacional do conjunto trator-recolhedora de feijão. Ciência Rural, vol. 38, n. 5, p. 1286-1291. http://dx.doi.org/10.1590/ S0103-84782008000500013

Silva, R.P., Cassia, M.T.C.; Voltarelli, M.A.; Compagnon, A.M. \& Furlani, C.E.A. (2013) - Qualidade da colheita mecanizada de feijão (Phaseolus vulgaris) em dois sistemas de preparo do solo. Revista Ciência Agronômica, vol. 44, n. 1, p. 61-69.

Souza, C.A.; Coelho, C.M.M.; Stefen, D.L.V.; Sachs, C. \& Figueiredo, B.P. (2010a) - Atributos morfométricos e componentes da produção do feijoeiro sob efeito de redutores de crescimento. Cientifica, vol. 38, n. 1/2, p. 30-38. http://dx.doi.org/10.15361/1984-5529.2010v38n1\%2F2p30+-+38

Souza, C.A.; Coelho, C.M.M.; Guidolin, A.F.; Engelsing, M.J. \& Bordin, L.C. (2010b) - Influência do ácido giberélico sobre a arquitetura de plantas de feijão no início de desenvolvimento. Acta Scientiarum Agronomy, vol. 32, n. 2, p. 325-332. http://dx.doi.org/10.4025/actasciagron.v32i2.3721

Streck, E.V.; Kämpf, N.; Dalmolin, R.S.D.; Klamt, E.; Nascimento, P.C. do; Schneider, P.; Giasson, E. \& Pinto, L.F.S. (2008) - Solos do Rio Grande do Sul. 2ae ed. rev. e ampl, Porto Alegre, Emater/RS, 222 p.

Swarnkar, S.K.; Poonam, S. \& Maurya, C.L. (2004) - Influence of plant growth regulators on aged seeds of soybean (Glycine max). Progressive Agriculture, vol. 4, n. 1, p. 66-68.

Taiz, L. \& Zeiger, E. (2013) - Fisiologia vegetal. 5ª ed. Porto Alegre, ArtMed, 954 p.

Vichiato, M.R.M.; Vichiato, M.; Castro, D.M.; Dutra, L.F. \& Pasqual, M. (2007) - Alongamento de plantas de Dendrobium nobile Lindl. com pulverização de ácido giberélico. Ciência e Agrotecnologia, vol. 31, n. 1, p. 1620. http://dx.doi.org/10.1590/S1413-70542007000100002 
Weiss, D. \& Ori, N. (2007) - Mechanisms of cross talk between gibberellin and other hormones. Plant Physiology, vol. 144, n. 3, p. 1240-1246. http://dx.doi.org/10.1104/pp.107.100370

Zhu, X.G.; Long, S.P. \& Ort, D.R. (2010) - Improving photosynthetic efficiency for greater yield. Annual Review of Plant Biology, vol. 61, p. 235-261. http://dx.doi.org/10.1146/annurev-arplant-042809-112206 